rics. The fact that part of the book contains a detailed study of the normal child ensures that it will often be found in the hands of those whose work lies outside hospitals.

The chapters, which cover a wide field, have been contributed by authorities of international standing. It will only be necessary to mention a few of the $2 \mathrm{I}$ contributors to indicate the calibre of this work. Professor Wallgren of Stockholm has contributed a chapter on tuberculosis, Sir James Spence on poliomyelitis, Professor Craig on 'The Preventative Paediatric Services' and Professor Alan Moncrieff on 'The Place of Child Health Industries in Medical Education and Research.' The present position in the investigation of congenital heart disease is well presented in a chapter containing much information which it would be laborious to obtain elsewhere. A detailed study of " The Normal Development of the Infant, by Professor Illingworth is followed by a brief but balanced contribution on child psychiatry by Dr. Mildred Creak. Most house-physicians who come across the chapter on chemotherapy by Professor Gaisford will find themselves reading carefully this most practical contribution. Many radiologists working in a general hospital with a children's department will read with interest the excellent section on radiology by Dr. 'Teall.

A work such as this has no need to maintain particular balance. None the less it seems fair to suggest that the problem of chondrodysplasias and the cranial dysostoses has received more consideration than some readers would wish.

The book itself is well produced and a delight to handle. The chapters are well illustrated, the radiographic reproductions being of a particularly high quality, and the references unusually comprehensive and up to date. It is to be hoped that there will be further editions of this useful work and that the new editor will maintain the enthusiasm that was contributed by the late Sir Leonard Parsons.

\section{THE DIAGNOSIS OF HYSTERIA}

By D. W. Abse, M.D., B.Sc., D.P.M. Pp. xii $\div$ I 2, with 7 illustrations. Bristol: John Wright \& Sons Ltd. I950. 8s. 6d.

The author of this monograph gives a clear explanation of Freudian psychopathology as applied to hysteria. His material consists mainly of cases collected in the Forces, particularly amongst Indian soldiers. 'This makes the book somewhat onesided. The cases described are interesting and illustrate the author's view clearly. On the part dealing with diagnosis one could have wished the author to be more systematic and less discursive in his case reports.

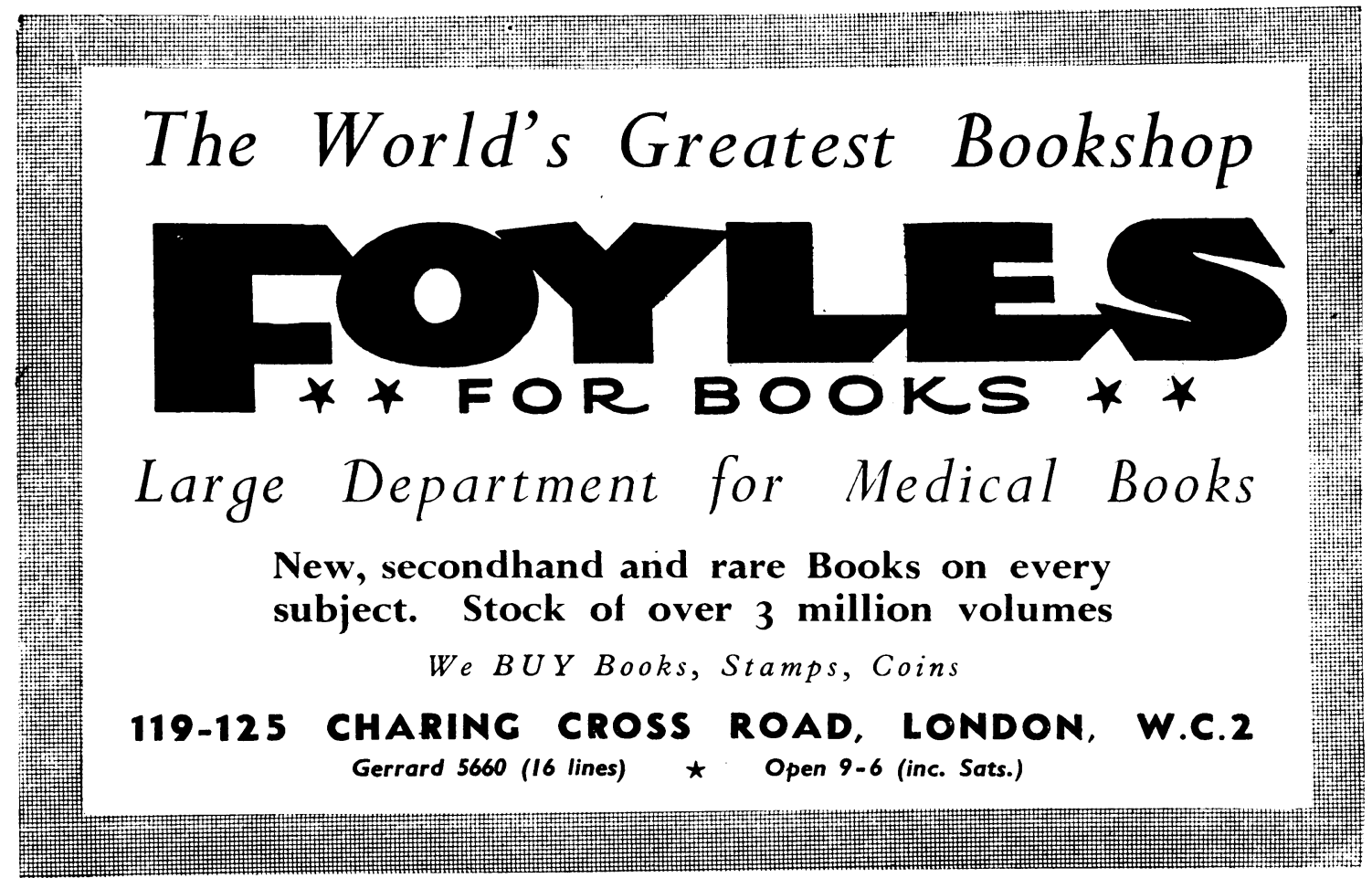

